Technological University Dublin

DƯBLIN

ARROW@TU Dublin

$2019-12-29$

\title{
Help-seeking From a Counsellor or Psychotherapist: a cross- sectional study of Irish adults
}

Damien Cassells

Technological University Dublin, damien.cassells@tudublin.ie

Follow this and additional works at: https://arrow.tudublin.ie/buschacart

Part of the Other Mental and Social Health Commons, and the Psychoanalysis and Psychotherapy Commons

\section{Recommended Citation}

Cassells, D. 2019. Help-Seeking from a Counsellor or Psychotherapist: A Cross-Sectional study of Irish Adults. International Journal of Happiness and Development, 5(4), 342-351. doi:10.1504/

IJHD.2019.104369

This Article is brought to you for free and open access by the School of Accounting and Finance at ARROW@TU Dublin. It has been accepted for inclusion in Articles by an authorized administrator of ARROW@TU Dublin. For more information, please contact arrow.admin@tudublin.ie, aisling.coyne@tudublin.ie, gerard.connolly@tudublin.ie. 
Help-seeking from a counsellor or psychotherapist: A cross-sectional study of Irish adults

By: Damien Cassells ${ }^{1}$

Correspondence: Dr. Damien Cassells, School of Accounting \& Finance, Technological University Dublin, Aungier St., Dublin 2, Ireland

Biography: Researcher with the Technological University Dublin and has published articles in Journals including the International Journal of Finance and Economics, Energy Policy and the Economic and Social Review.

${ }^{1}$ Correspondence: Dr. Damien Cassells, School of Accounting \& Finance, Technological University Dublin, Aungier St., Dublin 2, Ireland 
Help-seeking from a counsellor or psychotherapist: A cross-sectional study of Irish adults

\begin{abstract}
The factors that contribute towards an individual seeking help from a counsellor or psychotherapist for a mental, nervous or emotional problem are explored in this study. A multivariate logistic regression is applied to analyse data from the 2006 National Psychological Wellbeing and Distress Survey. Individuals living in rural areas and in towns with populations of between 5,000 and 10,000 people are found to be less likely to seek counselling, relative to individuals living in Dublin city. Respondents earning the lowest income were less likely to enter therapy compared with respondents earning the highest, while having private health insurance increased the probability of a respondent entering therapy. Individuals aged between 18 and 39 years and between 50 and 64 years are more likely to seek the help of a counsellor. Finally, attending a general practitioner, psychologist, social worker, or member of the clergy increased the likelihood of an individual seeking help from a counsellor or psychotherapist. No such effect was found for attending either a psychiatrist or nurse.
\end{abstract}

Keywords: Barriers to counselling; psychotherapy; help-seeking; Irish adults; logistic regression; happiness; emotional well-being; psychological problem; mental health. 


\section{Introduction and existing literature}

Most individuals will experience some level of anxiety throughout their lives and it is often this underlying feeling of tension that motivates clients to present for therapy (Morgan, 1973). Bower et al. (2003) suggest that relative to attending a general practitioner, presenting to a counsellor with an emotional problem will lead to an improvement in the client's condition, yet many individuals will choose not to seek such help. Kumar and Chaturvedi (2018) highlight the link between stress and increased suicide attempts amongst University students. UNICEF Ireland (2011) reports that $86 \%$ of young people in Ireland claim to have suffered with a mental health issue, while only $18 \%$ of the same cohort who report ongoing mental health issues sought professional assistance in managing their condition. Resistance to help-seeking for psychological or mental health issues is not unique to Ireland. Andrews et al. (1999) highlight that $62 \%$ of Australian individuals with a mental health disorder did not use the help of a mental health professional, while Zachrisson et al. (2006) in a study of Norwegian teenagers state that only one in three of those teenagers who were experiencing high levels of anxiety and depression actually consulted with a mental health professional.

The existing literature proposes several factors that may act as barriers for clients seeking professional assistance for emotional problems. McKay et al. (1996) suggest that men in western culture are less likely than women to acquire help for mental health issues such as depression, while Möller-Leimkühler (2002) argue that men are less likely than women to consult with any health care professional, particularly in relation to emotional problems. Wrigley et al. (2005), using a logistic regression 
model, report no differentiation between the genders in relation to help-seeking for psychological issues in Australia. Berger et al. (2005), in analysing a sample of males in the US, conclude that older men tend to have more positive attitudes toward psychological help, relative to younger males. Tijhuis et al. (1990), using a sample of over 10,000 Dutch adults, find that being younger, having higher levels of income and educational attainment are all positively linked with seeking help for emotional problems.

Oliver et al. (2005) examine the relationship between the scores obtained by individuals in the UK on the General Health Questionnaire (GHQ-12) and their attitudes to help-seeking and report that for every one unit increase in the GHQ-12 score, the likelihood of the individual seeking help increased by 10\%. Fuller et al. (2000) conclude that a culture of self-reliance and stoicism amongst people living in rural and remote communities in Australia contribute to a resistance to seeking help from professionals, while an associated stigma attached to mental health services is also noted as being an impediment to help-seeking. Neighbors et al. (1998), using a logistic regression model, examine the role of African American ministers in help-seeking of black Americans for emotional problems and conclude that, regardless of the presenting issues, those who get help from the clergy are less likely to seek help professionally. Kane and Williams (2000) report that Anglo Catholics in south Florida prefer to seek help from a professional rather than the clergy, with the opposite result reported for Hispanic Catholics.

This appears to be the first attempt to model the help-seeking behaviours of Irish adults and the motivation behind the work stems from several sources. Firstly, the gap 
between the need for help for emotional issues and the receiving of it, (as mentioned earlier in this section) is alarming and is deserving of an empirical investigation. Secondly, a recent OECD report suggests that mental health issues cost the Irish economy over $€ 8$ billion per annum and calls for priority to be given to mental health issues (OECD/EU, 2018). Finally, much of the previous literature has focused on research questions which reflected respondents' attitudes to help-seeking (Oliver et al., 2005; Wrigley et al., 2005), while also often using sub-samples of the population such as rural dwellers (Wrigley et al., 2005) or students (Eisenberg et al., 2007; Rickwood et al., 2007). However, this study looks at the actual help-seeking behaviours (as opposed to the attitudes to help-seeking), while utilising a sample of the Irish adult population.

\section{Methods}

Design

Irish adults were chosen as the sample for this study, as Ireland has the third highest rates of mental health illness in Europe and also has rates of depression that exceed the European average (OECD/EU, 2018). The 2006 National Psychological Wellbeing and Distress Survey (NPWDS) is the cross-sectional data set analysed in this study. The NPWDS was administered by the Economic and Social Research Institute (ERSI) on behalf of the Health Research Board (HRB) in an attempt to quantify the extent of mental health problems amongst Irish adults (Tedstone Doherty et al., 2008) ${ }^{2}$.

\footnotetext{
${ }^{2}$ The information on the method is drawn from Tedstone Doherty et al. (2008) who produced an initial report on behalf of the HRB.
} 


\section{Sample and procedure}

The survey only included adults over 18 years of age and living in private accommodation in the Republic of Ireland. A telephone survey methodology of the general population was utilised and telephone numbers were drawn on a random basis. Following on from the surveys, the sample was adjusted to allow for overrepresentation or underrepresentation of specific subgroups (age, gender, marital status, region, education and location) in the sample. In all, 2,711 individuals are included in the sample for this study.

\section{Measures}

The socio-demographic variables utilised in this analysis include gender, age, marital status, regions, number of dependents, employment, income, educational attainment and medical insurance. Respondents also completed the GHQ-12 survey to measure psychological distress. The GHQ-12 is a self-reported screening instrument that is often used in the dettection of psychiatric and pscyological issues (Goldberg, 1978). This variable has been constructed based on the bimodal (0-0-1-1) scoring system, therefore allowing for a maximum score of 12 . In relation to help-seeking, respondents were questioned on attending their general practitioner for emotional problems and also if they had interacted with other mental health care professionals or services, such as a psychologist, a psychiatrist a counselor or psychotherapist, or psychiatric hospitals. 


\section{Statistical analysis}

The data was coded to generate binary variables from qualitative data for inclusion in a logistic regression model, which is the appropriate model to use when the dependent variable is binary in nature (Studenmund, 2017). A multivariate logistic regression, with attending either a counsellor or psychotherapist in the previous twelve months as the dependent variable, was estimated to establish the relevant factors that contributed to respondents presenting for therapy. The explanatory variables modelled include measures of age, income, region, gender, medical insurance and the GHQ-12 score of the respondent.

\section{Results}

Sample characteristics

The total sample size is 2,711 individuals, with $43 \%$ of the sample being male. In terms of regional dispersion of the sample, $30 \%$ of respondents live in a rural location with $20 \%$ located in either the city or county of Dublin. The majority of respondents $(63 \%)$ are married, with just over $20 \%$ having never been married. The average number of children per household is under one $($ mean $=0.80$, standard deviation $=1.18)$, with eight being the most children in a household. In relation to mental health issues, the average GHQ-12 score was just over one (mean $=1.08$, standard deviation $=2.21)$, with just $3 \%$ of those sampled reporting a score of eight or above. 
Table I contains the breakdown of where respondents who were experiencing a mental, emotional or nervous problem sought help from. In total, 372 individuals (14\%) reported experiencing a mental, nervous or emotional problem in the previous year with $35 \%$ of these individuals being male. Of this group, $143(38 \%)$ received no professional input from a mental health or healthcare professional, while just under $5 \%$ sought out help from more than one source. Of the remaining $62 \%$ who chose to seek help, over a quarter (28\%) attended their general practitioner with just $18 \%$ choosing to utilise the help of a counsellor or psychotherapist. Of the group that attended a counsellor or psychotherapist, $37 \%$ were male and $32 \%$ of these individuals also attended their general practitioner for a mental, emotional or nervous problem.

\section{Table I here}

\section{Logistic regression analysis}

The results from the logistic regression predicting help-seeking from a counsellor or psychotherapist are presented in Table II, which also contains the full list of the variables included in the study. The association between socio-demographic variables and attending other mental health professionals and services, with help-seeking from a counsellor or psychotherapist is examined. The variables most strongly linked with presenting for therapy include age, education and attending a general practitioner, social worker or member of the clergy. No evidence was found that attending a psychiatrist, nurse or a psychiatric hospital is associated with working with a therapist. 


\section{Table II here}

Neither gender nor marital status has explanatory power in the model, with all associated p-values exceeding both the 5\% and $10 \%$ cut-off points. Respondents living in rural areas $(p<0.05)$ and in towns with populations of between 5,000 and 10,000 people $(\mathrm{p}<0.1)$ are less likely to present to a counsellor or psychotherapist, relative to a respondent living in Dublin city. These are the only locations found to increase or decrease the likelihood of attending therapy. Relative to individuals over the age of 65 , respondents aged between 18 and 29 years are over 20 times more likely $(p<0.1)$ to receive therapy. This age group are the most likely to have received counselling but similar effects are also found for individuals in the 30 to $39(\mathrm{p}<0.1)$ and 50 to 64 (p < 0.1 ) age brackets. In relation to income, only one income category has a predictive effect with those individuals with the lowest weekly earnings (less than €300) being $85 \%$ less likely $(\mathrm{p}=0.074)$ to attend a counsellor or psychotherapist in the previous year, relative to the wealthiest individuals sampled (earning over $€ 1,249$ per week). With respect to educational attainment and relative to those individuals who hold a third level qualification, respondents whose highest level of educational attainment is the Junior Certificate (equivalent to the GCSE in the UK) are almost twice as likely ( $p=$ 0.073 ) to receive therapy. Respondents with private health insurance are also more likely $(\mathrm{P}<0.1)$ to be attending therapy, relative to individuals without private medical cover.

In relation to mental health, for every one unit increase in the GHQ-12 score, the likelihood of attending a counsellor or psychotherapist increased by $12 \%(\mathrm{p}<0.05)$. 
Being a patient in day care centre in the mental health services in the previous year increased the chances of the individual presenting for counselling or psychotherapy $(p=$ 0.052). No such effect is reported for attending an outpatient clinic or day hospital in the mental health services or a psychiatric hospital. Taking prescribed medication for a mental, emotional or nervous problem is positively associated with receiving counselling $(p<0.05)$. With respect to the other branches of the mental health services, individuals who attended their general practitioner for a mental, nervous or emotional problem were found to be over six times $(\mathrm{p}<0.01)$ more likely to also attend a counsellor or psychotherapist, relative to respondents who had not attended their general practitioner for such a reason. Similar outcomes were reported for attending a psychologist $(p=0.028)$, social worker $(p=0.008)$ and a member of the clergy $(p=$ 0.015). No equivalent effect was found for attending a psychiatrist or nurse. Finally, respondents who use the internet (compared with respondents who don't use the internet) for a source of information on mental health were found to be more likely ( $\mathrm{p}<$ $0.05)$ to work with a counsellor or psychotherapist.

\section{Discussion}

This study examines the factors that contribute towards Irish adults seeking help from a counsellor or psychotherapist for a mental, emotional or nervous problem. In line with earlier studies (Oliver et al., 2005; Wrigley et al., 2005), socio-demographic variables are used to examine potential barriers to help-seeking from a therapist. However, it appears that few studies have explored the possible relationships between individuals 
presenting to both a counsellor or psychotherapist and other health care professionals and services for emotional issues.

One of the key findings of this study is that gender does not have a significant impact upon the likelihood of an individual attending therapy. This supports the work of Wrigley et al. (2005) but is not consistent with the some of the existing literature, with several authors (McKay et al., 1996; Möller-Leimkühler, 2002) pointing to a lower take-up of counselling by men. This finding may possibly be due to the amount of males sampled who received counselling, with $37 \%$ of the individuals presenting for therapy being male. Similar to the findings of Tijhuis et al. (1990), the youngest cohort sampled (between 18 to 29 years) are the most likely to be found in the counselling room. In line with the work of Fuller et al. (2000), individuals in rural communities are less likely to enter into a therapeutic relationship. The same arguments of self-reliance and stoicism as outlined in the Australian study could also be applied in the case of Ireland. Contrary to the findings of Eisenberg et al. (2007), having private health insurance is found to be a significant factor in clients choosing to seek help from a psychotherapist. This may in part be explained by the various health insurance packages that now contribute towards counselling and psychotherapy. There is no effect found for having a medical card and this may possibly be due to the lack of government funded counselling services in Ireland.

In line with the finding of Oliver et al. (2005) in the case of the UK, respondents with higher scores on the GHQ-12 scale tended to be more likely to be in therapy, while individuals who were prescribed medication for mental health purposes also had increased chances of working with a counsellor. There is striking evidence in relation 
to links between attending a therapist and other health professionals and services. Aside from psychiatrists and nurses, attending other health care professionals increases the probability of an individual attending counselling. This result coupled with the findings of no relationship between attending an outpatient clinic or day hospital in the mental health services, or a psychiatric hospital, and receiving counselling requires further analysis in future studies. Although no data was gathered on referrals, it may be the case that social workers, general practitioners, psychologists and members of the clergy (contrary to Neighbors et al., 1998) have a more integrated relationship with the counselling profession in comparison with psychiatrists and nurses and perhaps promote counselling among their patients. Potentially a more integrated approach between the services would serve the needs of clients better, with each profession acting as a gatekeeper for the other, much in keeping with the gatekeeper models proposed by both Wilson and Deane (2001) in the case of US Universities, and Hunt and Eisenberg (2010) for second level students in Australia. Finally, and in relation to improving mental health awareness, there is evidence of a positive relationship between use of the internet for health information and respondents seeking the help of a counsellor. This finding corresponds with the ethos of Rickwood et al. (2007), who promote the use of the internet in reducing the stigmas associated with mental health in Australia.

The results outlined here also provide useful information that can be guided towards policy development. In relation to rural Ireland, more behavioural studies could be conducted to establish why the uptake of professional services for emotional problems is lower in the rural regions when compared with urban areas. As Oliver et al. (2005) suggests, there is a need to also establish what beliefs prohibit people seeking 
help and if these individuals are at greater risk of harm as a result. Wrigley et al. (2005) argue for an improvement in mental health literacy, a policy that could also be implemented for the general population, not just those living in rural areas.

The other key issue arising from this research is the apparent lack of connectivity between the psychiatric and counselling services. Buchanan (2003) outlines the history of the rivalry between these professions. It could easily be argued that some form of collaborative approach between these caring professions would allow for better outcomes for the users of these services, while it may also be the case that one profession could be possibly viewed as a substitute for the other, where in reality they are complementary services. Such a policy may have to be government led and supported by both professions.

\section{Conclusion}

To the best of the author's knowledge, this is the first attempt to estimate a help-seeking model in relation to counselling and psychotherapy using Irish data. The majority of the key findings of this study are much in line with earlier work, most notably in relation to location and the GHQ-12 survey. The finding of the lack of linkage between psychiatry, the psychiatric services and counselling and psychotherapy warrants future exploration.

Despite the usefulness of the findings, there are some limitations worth noting. Firstly, the data is cross-sectional in nature. Panel data examining the mental health choices and outcomes for individuals over time would allow for an examination of any 
potential trends. Secondly, the majority of data is gathered via self-reporting, which potentially has an inherent bias associated with it. Finally, in relation to limitations, further study is required to examine the relationships between counselling and the other health care professions. Data on referrals would provide a more comprehensive understanding of the interactions between the various health services.

In conclusion, it is evident that younger, wealthier individuals with private health insurance, who use the internet to stay informed about health matters and who are living in the more populated areas of Ireland are more likely to be help-seekers, in relation to counselling and psychotherapy. Finally, no evidence is provided of links between using the Irish psychiatric services and counselling services, which could potentially be improved upon through the implementation of a gatekeeper scheme between the professions. 


\section{References}

Andrews, G., W. Hall, W., Teesson, M. and Henderson, S. (1999) National survey of mental health and wellbeing report 2: The mental health of Australians, Department of Health and Ageing.

Berger, J., Levant, R., McMillan, K., Kelleher, W. and Sellers A. (2005) 'Impact of gender role conflict, traditional masculinity ideology, alexithymia and age on men's attitudes toward psychological help seeking', Psychology of Men and Masculinity, Vol. 6 No. 1, pp.73-78.

Bower, P., Rowland N. and Hardy R. (2003) 'The clinical effectiveness of counselling in primary care: A systematic review and meta-analysis', Psychological Medicine, Vol. 33 No. 2, pp.203-215.

Buchanan, R. (2003) 'Legislative warriors: American psychiatrists, psychologists, and competing claims over psychotherapy in the 1950s, Journal of the History of Behavioral Sciences, Vol. 39 No. 3, pp.225-249.

Eisenberg, D., Golberstein, E. and Gollust, S. (2007) 'Help-seeking and access to mental health care in a university student population', Medical Care, Vol. 45 No. 7, pp.594-601.

Fuller, J., Edwards, J., Procter, N. and Moss, J. (2000). 'How definition of mental health problems can influence help seeking in rural and remote communities', Australian Journal of Rural Health, Vol. 8 No. 3, pp. 148-153.

Goldberg, D. (1978). GHQ-12, NFER-Nelson, London. 
Hunt, J. and Eisenberg, D. (2010) 'Mental health problems and help-seeking behaviour among college students', Journal of Adolescent Health, Vol. 46 No. 1, pp.3-10.

Kane, M. and Williams, M. (2000) 'Perceptions of south Florida hispanic and anglo catholics: From whom would they seek help?', Journal of Religion and Health, Vol. 39 No. 2, pp.107-121.

Kumar, K. and Chaturvedi, R. (2018) 'An empirical study of social support, stress and life satisfaction among engineering graduates: Mediating role of perceived work/study life balance', International Journal of Happiness and Development, Vol. 4 No. 1, pp.25 $-39$.

McKay, J., Rutherford, M., Cacciola, J. and Kabasakalian-McKay, R. (1996) ‘Gender differences in the relapse experiences of cocaine patients', Journal of Nervous and Mental Disease, Vol. 184 No. 10, pp.616-622.

Möller-Leimkühler, A. (2002) 'Barriers to help-seeking by men: A review of sociocultural and clinical literature with particular reference to depression', Journal of Affective Disorders, Vol. 71 No. 1-3, pp.1-9.

Morgan, A. (1973) 'Minor tranquilizers, hypnotics and seductives', The American Journal of Nursing, Vol. 73 No. 7, pp.1220-1222.

Neighbors, H., Musick, M. and William, D. (1998) 'The African American minister as a source of help for serious personal crisis: Bridge or barrier to mental health care?', Health Education and Behaviour, Vol. 25 No. 6, pp.759-777.

OECD/EU (2018). 'Health at a glance: Europe 2018: State of health in the EU cycle. OECD Publishing, Paris. 
Oliver, M., Pearson, N., Coe, N. and Gunnell, D. (2005). 'Help-seeking behaviour in men and women with common mental health problems: Cross-sectional study', The British Journal of Psychiatry, Vol. 186 No. 4, pp.297-301.

Rickwood, D., Deane, F. and Wilson, C. (2007) 'When and how do young people seek professional help for mental health problems?', Medical Journal of Australia, Vol. 187 No. 7, pp.S35-S39.

Studenmund, A. (2017) A Practical guide to using econometrics, $7^{\text {th }}$ ed., Pearson, London.

Tedstone Doherty, D., Moran, R., \& Kartalova-O’Doherty, Y. (2008) Psychological distress, mental health problems and use of health services in Ireland. Health Research Board, Dublin.

Tijhuis, M., Peters, L. and Foets, M. (1990) 'An orientation toward help-seeking for emotional problems', Social Science and Medicine, Vol. 31 No. 9, pp.989-995.

UNICEF Ireland (2011) Changing the future: experiencing adolescence in contemporary Ireland: Mental health. UNICEF Ireland, Dublin.

Wilson, C. and Deane, F. (2001) 'Adolescent opinions about reducing help-seeking barriers and increasing appropriate help engagement', Journal of Educational and Psychological Consultation, Vol. 12, No. 4, pp.345-364.

Wrigley, S., Jackson, H., Judd, F. and Komiti, A. (2005) 'Role of stigma and attitudes toward help-seeking from a general practitioner for mental health problems in a rural town', Australian and New Zealand Journal of Psychiatry, Vol. 39 No. 6, pp.514-521. 
Zachrisson, H., Rödje, K. and Mykletun, A. (2006) 'Utilization of health services in relation to mental health problems in adolescents: A population based survey'. $B M C$ Public Health, Vol. 6 No. 1, pp.34-40. 
Table I: Help-seeking for individuals with a mental, nervous or emotional problem.

Source of Help Number of Respondents $\quad$ Percentage of Respondents

\begin{tabular}{lcc}
\hline Received No Help & 143 & $38.44 \%$ \\
General Practitioner & 64 & $17.20 \%$ \\
Psychiatrist & 42 & $11.29 \%$ \\
Counsellor/Psychotherapist & 42 & $11.29 \%$ \\
Nurse & 39 & $10.48 \%$ \\
Social Worker & 23 & $6.18 \%$ \\
Clergy & 19 & $5.11 \%$ \\
Psychologist & 18 & $4.84 \%$ \\
More Than One Source & 18 & $4.84 \%$ \\
\hline
\end{tabular}

Data source: National Psychological Wellbeing and Distress Survey, 2006. 
Table II: Odds-ratios (OR), p-values (P) and confidence intervals (CI) for a multivariate logistic regression with attending a counsellor or psychotherapist as the dependent variable.

\begin{tabular}{|c|c|c|c|c|}
\hline \multirow[t]{2}{*}{ Predictor } & \multirow[t]{2}{*}{ OR } & \multirow[t]{2}{*}{$\mathbf{P}$} & \multicolumn{2}{|c|}{$95 \% \mathrm{CI}$} \\
\hline & & & Lower & Upper \\
\hline Male & 0.78 & 0.604 & 0.31 & 1.99 \\
\hline Separated & 1.32 & 0.748 & 0.24 & 7.29 \\
\hline Divorced & 2.95 & 0.171 & 0.63 & 13.92 \\
\hline Partner & 0.85 & 0.900 & 0.06 & 11.35 \\
\hline Widowed & 1.59 & 0.705 & 0.14 & 17.57 \\
\hline Never Married & 0.46 & 0.264 & 0.12 & 1.79 \\
\hline Hours Worked (Per Week) & 0.99 & 0.608 & 0.95 & 1.03 \\
\hline Rural (Open Country) & 0.26 & $0.044^{* *}$ & 0.07 & 0.96 \\
\hline Village $(<1,500$ people $)$ & 0.30 & 0.174 & 0.05 & 1.70 \\
\hline Town 1 ( $\geq 1,500$ and $<3,000$ People $)$ & 0.24 & 0.328 & 0.01 & 4.19 \\
\hline Town $2(\geq 3,000$ and $<5,000$ People $)$ & 1.33 & 0.790 & 0.16 & 11.14 \\
\hline Town 3 ( $\geq 5,000$ and $<10,000$ People) & 0.09 & $0.069^{*}$ & 0.01 & 1.20 \\
\hline Town 4 ( $\geq 10,000$ People) & 0.66 & 0.496 & 0.20 & 2.19 \\
\hline City (Limerick, Cork, Waterford, Galway) & 0.83 & 0.771 & 0.24 & 2.92 \\
\hline Dublin County & 1.19 & 0.795 & 0.31 & 4.54 \\
\hline Children (Number of Dependents) & 0.79 & 0.234 & 0.54 & 1.16 \\
\hline Age 1 ( $>17$ and $<30$ Years of Age) & 21.72 & $0.066^{*}$ & 0.82 & 577.69 \\
\hline Age 2 ( $\geq 30$ and $<40$ Years of Age) & 13.91 & $0.097^{*}$ & $0.62)$ & 310.90 \\
\hline
\end{tabular}


Table II (continued): Odds-ratios (OR), p-values (P) and confidence intervals (CI) for a multivariate logistic regression with attending a counsellor or psychotherapist as the dependent variable.

\begin{tabular}{|c|c|c|c|c|}
\hline \multirow[t]{2}{*}{ Predictor } & \multirow[t]{2}{*}{ OR } & \multirow[t]{2}{*}{$\mathbf{P}$} & \multicolumn{2}{|c|}{$95 \% \mathrm{CI}$} \\
\hline & & & Lower & Upper \\
\hline Age $3(\geq 40$ and $<50$ Years of Age $)$ & 11.02 & 0.115 & 0.56 & 217.82 \\
\hline Age $4(\geq 50$ and $<65$ Years of Age $)$ & 11.16 & $0.095^{*}$ & 0.66 & 189.24 \\
\hline Employee & 1.15 & 0.823 & 0.35 & 3.78 \\
\hline Retired & 0.61 & 0.638 & 0.08 & 4.88 \\
\hline Unemployed & 0.45 & 0.527 & 0.04 & 5.35 \\
\hline Student & 2.15 & 0.495 & 0.24 & 19.50 \\
\hline Income $1(<€ 300$ Per Week $)$ & 0.15 & $0.074^{*}$ & 0.02 & 1.21 \\
\hline Income $2(\geq € 300$ and $<€ 400$ Per Week) & 0.24 & 0.133 & 0.04 & 1.54 \\
\hline Income 3 ( $\geq € 400$ and $<€ 500$ Per Week) & 0.80 & 0.768 & 0.19 & 3.46 \\
\hline Income $4(\geq € 500$ and $<€ 750$ Per Week) & 1.10 & 0.879 & 0.32 & 3.78 \\
\hline Income 5 ( $\geq € 750$ and $<€ 900$ Per Week) & 1.33 & 0.662 & 0.38 & 4.69 \\
\hline Income $6(\geq € 900$ and $<€ 1250$ Per Week) & 1.42 & 0.620 & 0.35 & 5.72 \\
\hline Primary (Highest Level of Education) & 0.98 & 0.982 & 0.17 & 5.75 \\
\hline Junior Cert (Highest Level of Education) & 2.87 & $0.073^{*}$ & 0.91 & 9.07 \\
\hline Leaving Cert (Highest Level of Education) & 0.60 & 0.439 & 0.17 & 2.18 \\
\hline Other $2^{\text {nd }}$ Level (Highest Level of Education) & 2.24 & 0.172 & 0.70 & 7.14 \\
\hline Medical Card & 1.89 & 0.284 & 0.59 & 6.03 \\
\hline Health Insurance & 2.70 & $0.071^{*}$ & 0.92 & 7.93 \\
\hline
\end{tabular}


Table II (continued): Odds-ratios (OR), p-values (P) and confidence intervals (CI) for a multivariate logistic regression with attending a counsellor or psychotherapist as the dependent variable.

\begin{tabular}{|c|c|c|c|c|}
\hline \multirow[t]{2}{*}{ Predictor } & \multirow[t]{2}{*}{ OR } & \multirow[t]{2}{*}{$\mathbf{P}$} & \multicolumn{2}{|c|}{$95 \% \mathrm{CI}$} \\
\hline & & & Lower & Upper \\
\hline GHQ-12 & 1.12 & $0.047^{* *}$ & 1.00 & 1.26 \\
\hline GP & 7.48 & $0.000^{* * *}$ & 2.63 & 21.26 \\
\hline Psychiatrist & 0.83 & 0.815 & 0.18 & 3.93 \\
\hline Nurse & 2.54 & 0.192 & 0.63 & 10.26 \\
\hline Psychologist & 5.70 & $0.028^{* *}$ & 1.21 & 26.95 \\
\hline Social Worker & 6.53 & $0.008^{* * *}$ & 1.64 & 25.92 \\
\hline Clergy & 8.21 & $0.015^{* *}$ & 1.50 & 44.90 \\
\hline Outpatient (Mental Health Services) & 0.81 & 0.767 & 0.20 & 3.23 \\
\hline Day Centre (Mental Health Services) & 6.70 & $0.052^{*}$ & 0.99 & 45.51 \\
\hline Day Hospital (Mental Health Services) & 0.75 & 0.771 & 0.11 & 5.26 \\
\hline Inpatient (Psychiatric Hospital) & 5.59 & 0.215 & 0.37 & 85.09 \\
\hline Medication (Prescribed for Mental Health) & 2.85 & $0.044^{* *}$ & 1.03 & 7.90 \\
\hline Internet (Used for Health Information) & 2.45 & $0.038^{* *}$ & 1.05 & 5.71 \\
\hline
\end{tabular}

Data source: National Psychological Wellbeing and Distress Survey, 2006.

${ }^{*} \mathrm{p}<0.1,{ }^{* *} \mathrm{p}<0.05,{ }^{* * *} \mathrm{p}<0.01$. Number of observations $=2,711$. The omitted categories for estimation are Married, Dublin City, Age 5 ( $\geq 65$ Years of Age), Income 7 ( $\geq € 1250$ Per Week) and Third Level (Highest Level of Education). 